\title{
Prediction of spontaneous closure of isolated ventricular septal defects in utero and postnatal life
}

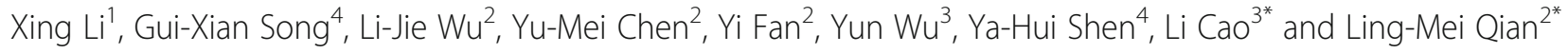

\begin{abstract}
Background: Ventricular septal defect (VSD) is a highly prevalent fetal congenital heart defect, which can become spontaneously closed during infancy. The current study aims to characterize fetal VSDs that were subsequently spontaneously closed in the first 2 years of life in eastern China.

Methods: Between January 2011 and December 2013, 257 fetal patients diagnosed with isolated VSD by fetal echocardiography at Nanjing Maternity and Child Health Care Hospital, China, were enrolled in the study. Subjects were divided into three groups: group 1 = persistent VSD; group 2 =closed after birth; group 3 =closed during gestation. Fetal echocardiography data, physical features at birth and follow-up outcomes for 2 years were compared to identify factors contributing to spontaneous closure (SC) of VSD. A predictive formula was applied to patients admitted to hospital in the first quarter of $2014(n=23)$ for validation.

Results: SC occurred in 42.8\% patients. Birth weight (3.095 $\pm 0.774,3.174 \pm 0.535,3.499 \pm 0.532 \mathrm{~kg}$ in groups 1,2 and 3, respectively) and defect diameter $(3.422 \pm 0.972,2.426 \pm 0.599,2.292 \pm 0.479 \mathrm{~mm}$, in groups 1, 2 and 3, respectively) showed statistically significant differences between the three groups $(P=0.004$ and $P=0.000$, respectively). Receiver operating characteristic (ROC) curves identified cut-off value for the defect diameter as 2. $55 \mathrm{~mm}$, and logistic regression analysis identified the SC probability $=\left(1+\exp -\left[-2.151-0.716^{*}\right.\right.$ birth weight +1 . $393^{*}$ diameter $\left.]\right)^{-1}$. Results indicated that male fetuses, full-term birth, muscular VSD, and defects without blood flow crossing the septum, have higher incidence of SC.
\end{abstract}

Conclusions: The major determinants of SC of isolated VSD are birth weight and diameter of the defect. In addition, VSD location may also affect the SC incidence.

Keywords: Ventricular septal defects, Spontaneous closure, Fetal echocardiography

\section{Background}

The incidence of congenital heart disease (CHD) in the western world is $0.3-1.2 \%$ of live births [1]. Ventricular septal defect (VSD) is the most common congenital heart defect, accounting for $20-30 \%$ of all congenital heart defects [2]. In a recent study, Zhao et al. [3] described a $2.66 \%$ prevalence of $\mathrm{CHD}$ at live birth in China using

\footnotetext{
*Correspondence: njcaoli7@hotmail.com; Imqian@njmu.edu.cn

${ }^{3}$ Department of Fetal Echocardiography, Nanjing Maternity and Child Health Care Hospital Affiliated to Nanjing Medical University, No.123 Tianfei Lane, Mochou Road, Nanjing, Jiangsu Province, China

${ }^{2}$ Department of Cardiology, The First Affiliated Hospital of Nanjing Medical University, No. 300 Guangzhou Road, Nanjing 210029, Jiangsu Province, China

Full list of author information is available at the end of the article
}

echocardiographic screening, and they also found that only a $1.21 \%$ prevalence of CHD that could be detected by clinical evaluation, with the most common CHD as VSD at a prevalence of $1.73 \%$. VSDs can occur alone or in combination with other cardiac defects. However, the majority of VSDs occur alone and referred to as "isolated" or "simple" [4], and the current study has therefore focused on isolated VSDs. VSDs are typically asymptomatic and often close spontaneously [5]. Two-dimensional echocardiography combined with pulsed Doppler or Doppler color flow mapping is a well-established technique to diagnose and localize fetal and infant VSDs. The present study utilized fetal echocardiography and state at birth to evaluate the incidence and timing of SC of VSD in patients 
who were diagnosed with VSD prenatally in eastern China. There have been a number of observational long-term follow-up studies on spontaneous closure (SC) of VSD [6-29], but few of these reports were followed up from the fetal period. Here, we present a long-term follow-up study in which subjects were followed up from the fetal period and summarized a prediction formula including factors influencing SC of VSD. We found that birth weight was a prognostic variable for SC of VSD, which was most useful for pediatricians, and that the defect diameter was another prognostic variable, which may provide useful information for obstetrician-gynaecologists to aid prenatal counseling.

\section{Methods}

\section{Study population}

A total of 5855 pregnant women underwent fetal echocardiography examination between January 2011 to December 2013 at the Fetal Echocardiography Department of Nanjing Maternity and Child Health Care Hospital, Nanjing, China. Of these women, 1168 cases had cardiac structural abnormalities, and 335 fetal patients diagnosed with isolated VSD were enrolled in current study.

\section{Indications for fetal echocardiography}

Pregnant women in the following status during their routine obstetric examination were recommended a further fetal echocardiography examination: suspected CHD on screening ultrasound during the second trimester; extracardiac anomalies on screening ultrasound; advanced maternal age; family history of CHD; increased nuchal translucency; fetal arrhythmia; chromosomal abnormality.

\section{Diagnostic criteria of VSD by echocardiography}

Two skilled sonographers (Li Cao and Yun Wu) conducted all the fetal echocardiography examinations using the Acuson Sequoia 512 ultrasound system (Siemens, Malvern, PA, USA) with a $3-5-\mathrm{MHz}$ phased-array transducer. Complete transthoracic two-dimensional, M-mode, continuous wave and pulsed wave Doppler and color Doppler echocardiographic examinations were performed. An echo dropout in the ventricular septum in twodimensional echocardiography was considered diagnostic of a VSD (Figs. 1 and 2). A typical systolic colored flame (Figs. 3 and 4) crossing the septum and in most cases a jet derived from pulsed Doppler confirmed the existence of the defect (however, if the shunt blood pressure is low, colored jet crossing the septum may not be detected). Extreme care was taken to determine location and width of defects. The diameter of VSD in two-dimensional and/or color flow mapping was measured in all planes and the largest diameter of VSD was recorded. Apical fourchamber, apical five-chamber, parasternal long- and shortaxis and subcostal positions were used to image the defect,

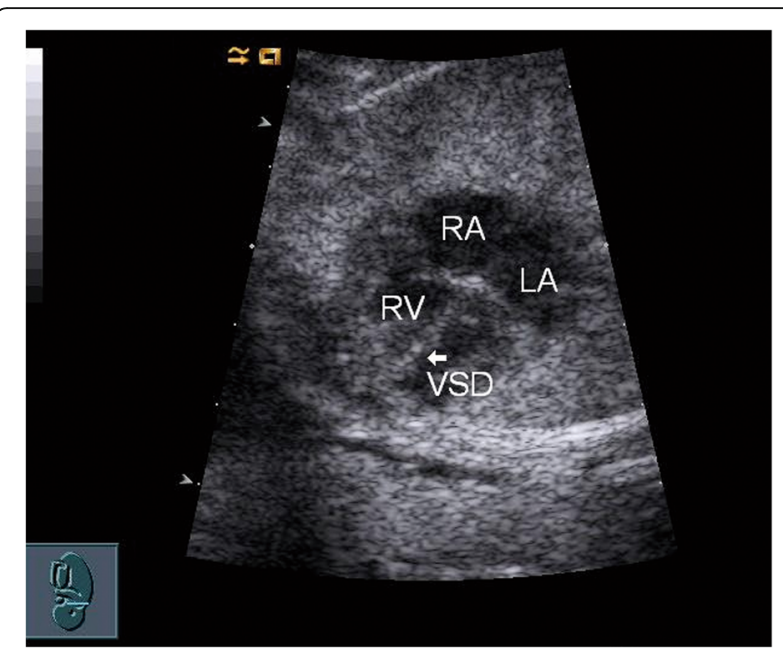

Fig. 1 White arrow indicates a small VSD detected by fetal echocardiography, and SC during follow-up

with a minimum of no less than three views. Defects were classified as perimembranous, muscular, subarterial or multiple types (more than one defect) [30]. Infants who had associated complex structural cardiovascular defects were excluded from the isolated VSD group.

\section{Follow-up studies}

Parental consents were obtained from the parents of each neonate. Detailed history of the neonates, parents and family members were taken by face-to-face or telephone interviewing of the parents. A fetal echocardiography reexamination in third trimester and repeated echocardiographies at the children's routine physical examinations at age 1, 3, 6 and 12 months of age depending on the growth and development condition of the

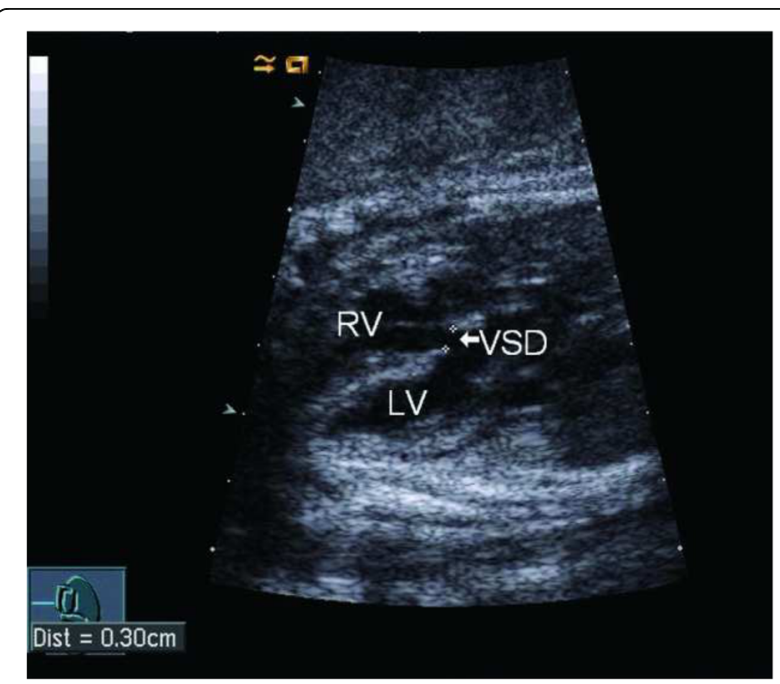

Fig. 2 White arrow indicates a large VSD detected by fetal echocardiography, and no SC during follow-up 


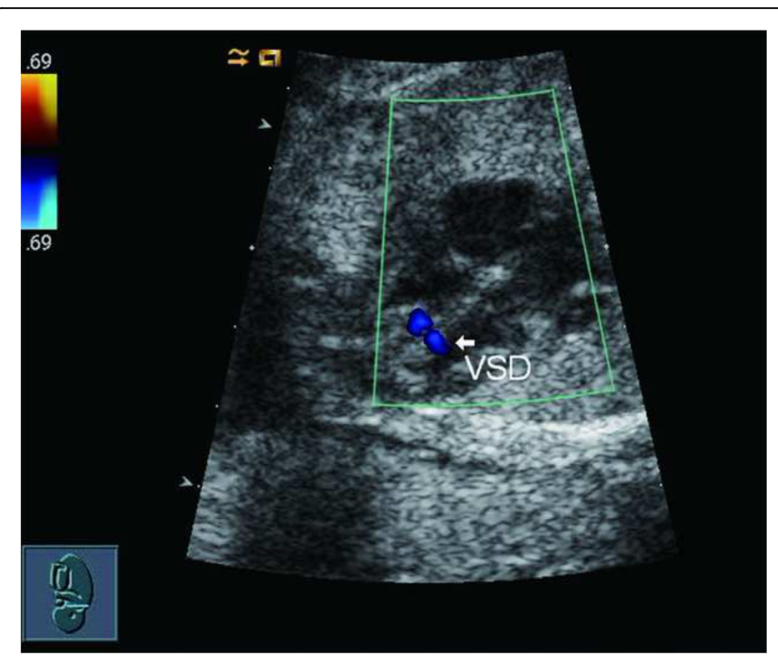

Fig. 3 Color Doppler echocardiographic examination of small VSD

children until the spontaneous or surgical closure of the VSD was confirmed, were recommended to all parents. Spontaneous closure occurred in patients without echo dropout in the septum and without detection of blood flow through the septum in echocardiography.

Data in the ultrasound records consisted of gestational weeks, maternal age, fetal heart rate, width of aorta and pulmonary artery, location and diameter of the defect, direction of the shunt. Questions in the interview included: (1) Did the defects close or not? (2) When did the spontaneous closure occur? (3) What treatments are used for those whose defects persist? (4) Gender and birth weight of the infancy. (5)Was there premature delivery? (6) Were there any infections or metabolic diseases during pregnancy? (7) Is there any family history of heart disease? Besides, fetal karyotype examination results of those who received amniocentesis were also collected.

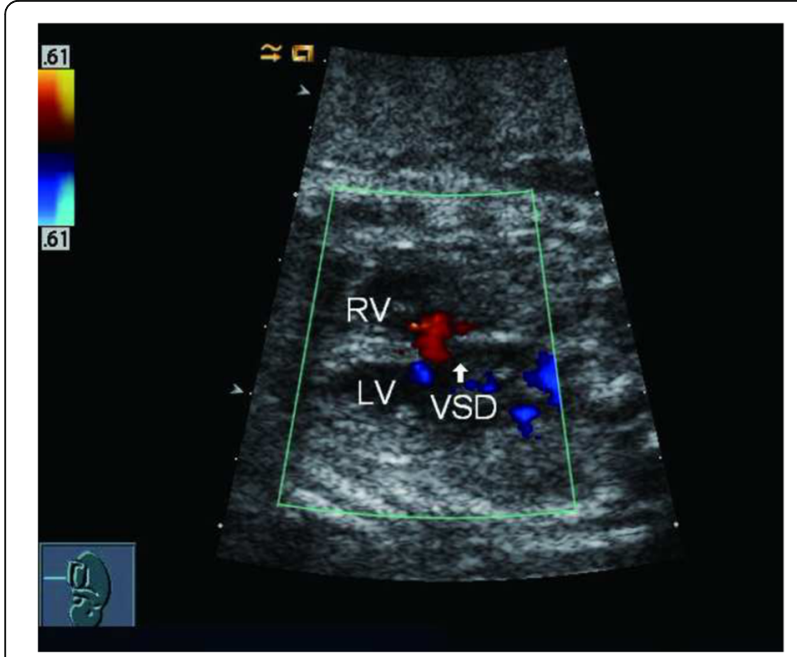

Fig. 4 Color Doppler echocardiographic examination of large VSD

\section{Validation study of the prediction formula}

In the second part of the study, the prediction formula was then applied to 23 patients, who were admitted to the hospital in the first quarter of 2014 in order to validate the derived prediction formula.

\section{Statistical analysis}

All data are expressed as mean \pm standard deviation (SD). The differences among the three groups were assessed using analysis of variance (ANOVA) for continuous variables, and student-neuman-keuls tests were applied for post-hoc comparisons. Comparisons between group 1, 2 and 3 were made using Chi-square tests for categorical variables. A $P$-value $<0.05$ was considered statistically significant. Statistically significant clinical and echocardiographic variables were subsequently evaluated by binary logistic regression analysis to identify independent predictors of outcome. Receiver operating characteristic (ROC) analysis was performed to assess the sensitivity and specificity of the diameter of the defect for predicting SC of VSD.

\section{Results}

A total of 335 fetal patients, referred for fetal echocardiographic examination and diagnosed with isolated VSD at Nanjing Maternity and Child Health Care Hospital between January 2011 and December 2013, were enrolled in this retrospective study. In spite of repeated efforts to contact the parents, 78 patients were lost to follow-up after the initial first or second visit. Follow-up was completed in 257 (76.7\%) patients. Outcomes for these patients are summarized in Fig. 5. According to whether the defect in ventricular septum was closed or not, children were divided into three groups: groups $1=$ defects not yet closed (this group included infants who died after birth because of VSD, and who underwent surgical intervention, and whose defects persisted by the time of follow up); group 2 = defects closed after birth; group 3 = defects were closed during gestation.

\section{General conditions}

Mean gestational age was $26.68 \pm 1.092$ weeks (range, 19-30 weeks) at the time when the fetuses were diagnosed with VSD. The average maternal age of the study population was $29.25 \pm 4.874$ years (range, $20-42$ years). Sex ratio for the patients was 82 males: 69 females. Percentages of different types of defects were as follows: perimembranous, 115 (78.8\%); muscular, 20 (13.7\%); subarterial, 7 (4.8\%); multiple, 4 (2.7\%). The average time when spontaneous closure occurred was $7.31 \pm$ 6.073 months. 


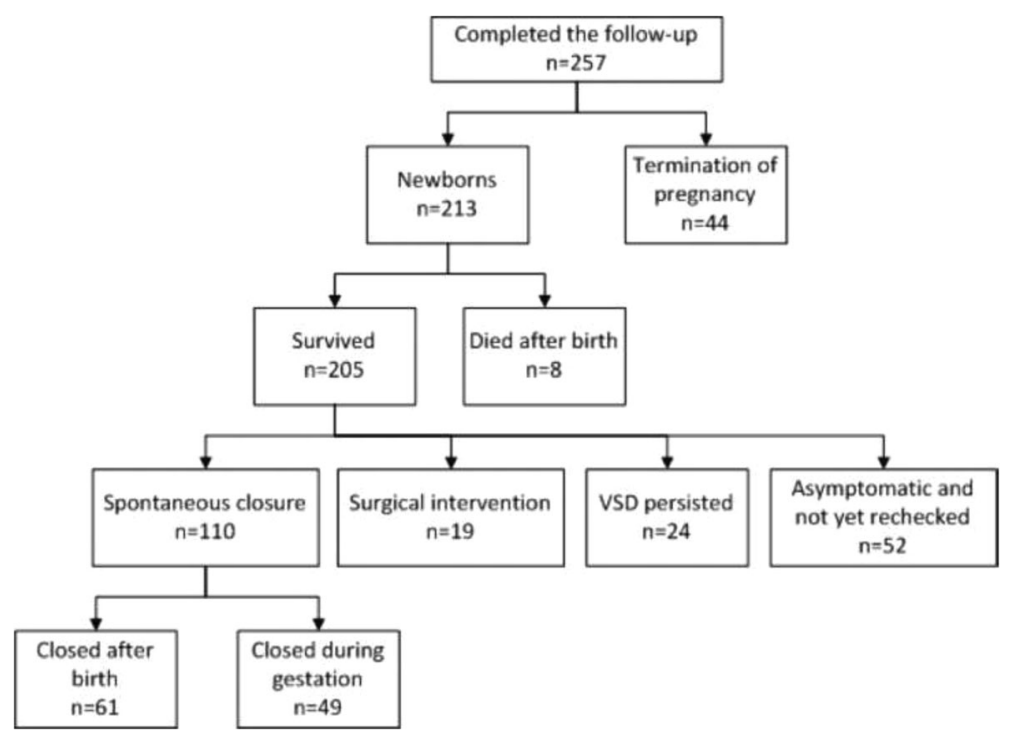

Fig. 5 Study flow chart for the outcome of fetuses with VSD after birth

\section{Clinical findings}

The birth weights and diameter of the defects between the three groups were significant different $(P=0.004$ and $P=0.000$, respectively), with the highest birth weights observed in patients whose defects closed within gestation and the largest diameter of the defectsin patients whose defects persisted (Table 1). The proportion of preterm birth was lower in group $3(P=0.058$; Table 2$)$. Furthermore, gender differences were noted between the groups, whereby male predominance was observed in group 3 (SC during gestation) and female predominance in group 1 (defects not closed), although these differences did not reach statistical significance (Table 2). SC rates at different locations are also detailed in Table 2. All the muscular defects have been closed, higher than rate of spontaneous closure (81.8-89\% at 12-month follow-up) of muscular VSD was reported in previous studies. There were 11 cases without detection of blood flow through the septum that experienced spontaneous closure.

\section{ROC curve}

When SC is defined as a state variable and the defect diameter is defined as a test variable, the value of state variable set to zero, a receiver operating characteristic curve can be achieved. Area under the curve is $0.842, P=0.000$. Cut-off value is $2.55 \mathrm{~mm}$. In this case, sensitivity $=0.800$, specificity $=0.718$ (Fig. 6).

\section{Logistic regression analysis}

To estimate the SC probability for a given defect diameter and birth weight, logistic regression analysis was used. After removing the impact of the defect location, birth weight was identified a protective factor [odds ratio (OR) value: $0.498 ; 95 \%$ CI $0.244,0.978$ ] while defect diameter was identified as a risk factor [OR value: 4.072; 95\% CI: $1.885,8.604$ ] for SC. The relationship between defect diameter plus birth weight and SC probability was described by the following prediction formula: $\quad$ probability $=(1+\exp \quad-[-2.151-0.716 *$ birth weight $+1.393 *$ diameter]) ${ }^{-1}$.

Table 1 Statistical results of quantitative data are shown in Table 1

\begin{tabular}{llllll}
\hline & & Group 1 & Group 2 & Group 3 & $P$ value \\
\hline Birth weight & $\mathrm{M} \pm \mathrm{SD}$ & $3.095 \pm 0.774$ & $3.174 \pm 0.535$ & $3.499 \pm 0.532$ & $0.004^{*}$ \\
& $95 \% \mathrm{Cl}$ & $(2.851,3.339)$ & $(3.035,3.313)$ & $(3.155,3.359)$ & $2.292 \pm 0.479$ \\
Diameter & $\mathrm{M} \pm \mathrm{SD}$ & $3.422 \pm 0.972$ & $2.426 \pm 0.599$ & $(2.154,2.429)$ & $30.000^{*}$ \\
& $95 \% \mathrm{Cl}$ & $(3.146,3.698)$ & $(2.273,2.579)$ & $4.45 \pm 4.282$ & 0.245 \\
Maternal age & $\mathrm{M} \pm \mathrm{SD}$ & $29.10 \pm 4.610$ & $28.43 \pm 5.393$ & $4.76 \pm 0.437$ & 0.193 \\
Aortic diameter & $\mathrm{M} \pm \mathrm{SD}$ & $4.62 \pm 0.585$ & $5.74 \pm 0.529$ & $5.60 \pm 0.481$ & 0.469 \\
Pulmonary artery diameter & $\mathrm{M} \pm \mathrm{SD}$ & $5.52 \pm 0.542$ & $146.92 \pm 7.957$ & 0.177 \\
Fetal heart rate & $\mathrm{M} \pm \mathrm{SD}$ & $145.65 \pm 8.089$ & $146.53 \pm 6.427$ & & 1456 \\
\hline
\end{tabular}


Table 2 Statistical results of qualitative data are shown in Table 2

\begin{tabular}{|c|c|c|c|c|c|}
\hline & & \multirow{2}{*}{$\begin{array}{l}\text { Group } 1 \\
\mathrm{n}(\%)\end{array}$} & \multirow{2}{*}{$\begin{array}{l}\text { Group } 2 \\
\mathrm{n}(\%)\end{array}$} & \multirow{2}{*}{$\begin{array}{l}\text { Group3 } \\
n(\%)\end{array}$} & \multirow[t]{2}{*}{$P$ value } \\
\hline & & & & & \\
\hline \multirow[t]{2}{*}{ Delivery } & Premature & 10/23 (43.5\%) & $10 / 23(43.5 \%)$ & $3 / 23(13.0 \%)$ & 0.058 \\
\hline & Mature & $32 / 127$ (25.2\%) & $51 / 127(40.2 \%)$ & $44 / 127$ (34.6\%) & \\
\hline \multirow[t]{2}{*}{ Gender } & Male & 18/82 (22.0\%) & $33 / 82(40.2 \%)$ & $31 / 82$ (37.8\%) & 0.119 \\
\hline & Female & $24 / 69$ (34.8\%) & $28 / 69$ (40.6\%) & $17 / 69(24.6 \%)$ & \\
\hline \multirow[t]{4}{*}{ Location } & Perimembranous & $34 / 115(29.6 \%)$ & 46/115 (40.0\%) & $35 / 115(30.4 \%)$ & $0.007^{*}$ \\
\hline & Muscular & 0/20 (0\%) & $11 / 20(55.0 \%)$ & 9/20 (45.0\%) & \\
\hline & Subpulmonary & $2 / 3(66.7 \%)$ & $0(0 \%)$ & $1 / 3(33.3 \%)$ & \\
\hline & Multiple & $2 / 4(50.0 \%)$ & $1 / 4(25 \%)$ & $1 / 4(25 \%)$ & \\
\hline \multirow[t]{4}{*}{ Shunt direction } & Left-to-right & 39/105 (37.1\%) & $30 / 105$ (28.6\%) & $36 / 105$ (34.3\%) & $0.011^{*}$ \\
\hline & Right-to-left & 4/14 (28.6\%) & $7 / 14(50 \%)$ & $3 / 14(21.4 \%)$ & \\
\hline & Bilateral & $6 / 28(21.4 \%)$ & 17/28 (60.7\%) & 5/28 (17.9\%) & \\
\hline & Not detected & $0(0 \%)$ & 7/11 (63.6\%) & 4/11 (36.4\%) & \\
\hline \multirow[t]{5}{*}{ Maternal disease } & No signs of disease & $39 / 129(30.2 \%)$ & $50 / 129(38.8 \%)$ & $40 / 129(31.0 \%)$ & 0.350 \\
\hline & Influenza & $5 / 13(38.5 \%)$ & 6/13 (46.2\%) & 2/13 (15.4\%) & \\
\hline & Hyperglycemia & 6/14 (42.9\%) & $3 / 14$ (21.4\%) & 5/14 (35.7\%) & \\
\hline & Hypertension & $1 / 3(33.3 \%)$ & 0 & $2 / 3(66.7 \%)$ & \\
\hline & Hyperthyreosis & 0/1 (0\%) & 1/1 (100\%) & 0/1 (0\%) & \\
\hline
\end{tabular}

\section{Verification of the prediction formula}

Follow-up outcome was compared with the probability calculated by our prediction formula, and 82.6\% (19/23) of the predicted results coincided with the actual outcomes (Tables 3 and 4). We used these data to draw a 3

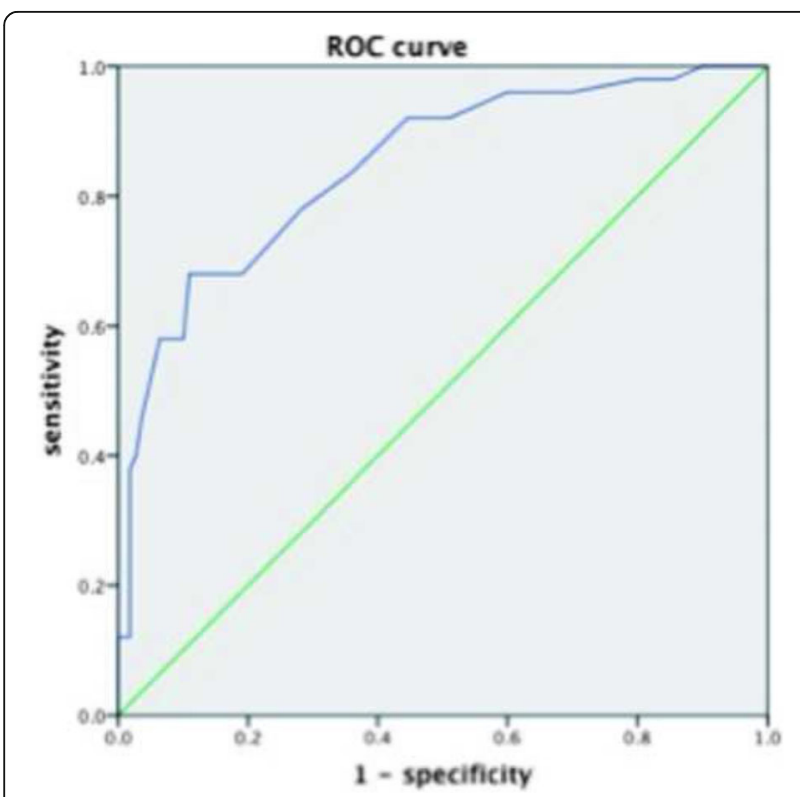

Fig. 6 When SC is defined as a state variable and the defect diameter is defined as a test variable, the value of state variable is set to zero, and a receiver operating characteristic (ROC) curve can be achieved. Area under the curve is $0.842 ; P=0.000$; Upper cut-off value $=2.55 \mathrm{~mm}$ dimensional scatterplot, diameter of the defect is $\mathrm{X}$ axis, $P$ value is $\mathrm{Y}$ axis and birth weight is $\mathrm{Z}$ axis. As we can see, with lager defect diameter and lower birth weight come with higher $P$ value, which means the defects are more likely to stay persistent (Fig. 7).

\section{Fetal karyotype of VSDs}

Karyotyping was performed in 80 cases: 71 (88.75\%) fetuses had a normal karyotype, and 9 (11.25\%) cases of chromosomal anomalies were identified. Among the cases with aneuploidy, there were 7 cases with trisomy 18, 1 case with Turner syndrome, and 1 case with balanced translocations. Seven of 9 fetuses with trisomy 18 presented with a perimembranous VSD, 1 case with a mixedtype VSD and 1 case had a muscular defect (Table 5).

\section{Discussion}

The present study was conducted in order to evaluate $\mathrm{SC}$ rate of isolated VSD and the clinical characteristics and prognosis of VSD patients from fetal age until 2 years after birth, in eastern China. While the incidence of VSD has increased in recent years, there has been advancement of fetal echocardiographic technology, allowing more accurate diagnosis of fetal congenital heart defects [31, 32]. Fetal heart examination is possible by transvaginal transducers as early as 9-10 weeks of gestation, and good quality transabdominal echo pictures are generally obtainable by 16 gestational weeks. In the current study, patients were evaluated during in second and early third trimester of pregnancy. Fetal cardiac 
Table 3 Verification: List of children whose defects spontaneously closed

\begin{tabular}{llllll}
\hline ID & Predicted probability & Actual outcome & Time of SC & Birth weight $(\mathrm{kg})$ & Defect diameter $(\mathrm{mm})$ \\
\hline 01 & 0.2873 & Closed & In gestation & 3.1 & 2.7 \\
02 & 0.3669 & Closed & In gestation & 3.4 & 2.9 \\
03 & 0.1889 & Closed & 6 months & 3.7 & 2.4 \\
04 & 0.3133 & Closed & 3 months & 3.15 & 2.6 \\
05 & 0.1926 & Closed & In gestation & 4.25 & 2.7 \\
06 & 0.1113 & Closed & Neonatal & 3.4 & 1.8 \\
07 & 0.1454 & Closed & 3 months & 3.75 & 2.2 \\
08 & 0.2818 & Closed & Neonatal & 3.75 & 2.8 \\
09 & 0.1033 & Closed & Neonatal & 4.1 & 2.1 \\
10 & 0.2598 & Closed & In gestation & 4.1 & 2.9 \\
11 & 0.5068 & Closed & 6 months & 2.6 & 2.9 \\
12 & 0.4700 & Closed & In gestation & 3 & 3 \\
13 & 0.0619 & Closed & In gestation & 4.1 & 3.7 \\
14 & 0.3049 & Closed & 6 month & 3.4 & 2.7 \\
15 & 0.1883 & Closed & 12 month & 3.9 & 2.5
\end{tabular}

SC spontaneous closure

In the binary logistic regression, spontaneous closure is defined as 0 , persisted defect is defined as 1 , and predicted probability stands for the possibility of persisted defects

The predicted possibilities of the patients whose defects closed spontaneously are all below 0.5 (except for patent No.11)

screening is typically carried out at $18-22$ gestational weeks, since fetal cardiac anatomical details, including ventriculoarterial connections, are possible to evaluate at this stage [33]. Subjects included in the present study were all in line with the indications for fetal echocardiography, ensuring efficient detection of CHD. Common referral indications include abnormal cardiac screening ultrasound, extracardiac anomalies shown on screening ultrasound, maternal diabetes, and family history of CHD [34].

In 1918, a French study reported the clinical findings in a young boy whose murmur and thrill disappeared at 5 years of age, documenting from first record of SC of VSD [35]. Here, we have reviewed reports on SC of VSD
1987 to 2015 from various countries, which have been detailed in Table 6 . Reported closure rates vary from 6 to $88.9 \%$ with size and location of VSD, age at presentation and patient population, and results from our study are consistent with previous reports $[6,8,9,18]$. SC of VSD is most common during the first year of life, with the likelihood of SC decreasing during adolescent years and adult life. It has been reported that the SC rate of patients with VSD not receiving surgical closure during childhood was as low as 6\% [17].

In line with many previous reports, perimembranous VSD was the most prevalent form of VSD, and muscular VSD had an obviously higher SC rate [8, 10-12, 15, 18, 20, 22]. However, the average diameter of muscular VSD was

Table 4 Verification: List of children whose defects didn't spontaneously close

\begin{tabular}{lllll}
\hline ID & Predicted probability & Actual outcome & Birth weight(kg) & Defect diameter(mm) \\
\hline 01 & 0.8469 & Thoracotomy surgery & 2 & 3.8 \\
02 & 0.6264 & Mortality & 2.5 & 3.2 \\
03 & 0.3467 & Mortality & 2.55 & 2.4 \\
04 & 0.4700 & Defect reduced & 3 & 3 \\
05 & 0.5496 & Defect persisted & 4.5 & 4 \\
06 & 0.7362 & Defect persisted & 3.15 & 3.9 \\
07 & 0.4056 & Defect reduced & 3.95 & 3.3 \\
08 & 0.7984 & Defect persisted & 3.05 & 4.1 \\
\hline
\end{tabular}

In the binary logistic regression, spontaneous closure is defined as 0 , persisted defect is defined as 1 , and predicted probability stands for the possibility of persisted defects

Patients with predicted possibility above 0.5 experienced surgery (No.01), mortality (No.02), or persistent defects (No.05,06.08), while patients with predicted possibility below 0.5 had reduced defects (No.04,07). Patient No.03 has Down's syndrome 


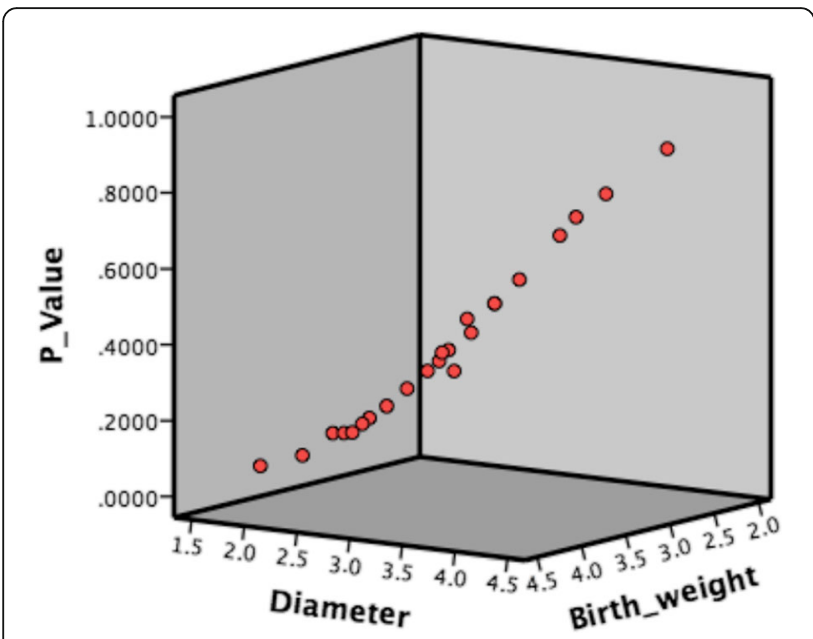

Fig. 7 A three dimensional scatterplot was drawn by SPSS, diameter of the defect is $X$ axis, $P$ value is $Y$ axis and birth weight is $Z$ axis. As we can see, with lager defect diameter and lower birth weight come with higher $P$ value, which means the defects are more likely to stay persistent

smaller than other types and none of the subjects required surgical intervention. The closure of muscular defects begins with septal muscle adherence, followed by obliteration of the defect by a fibrous tissue plug [36, 37]. In closure of membranous defects, the VSD is "covered" by tricuspid valve tissue [38, 39], Nir [39] also suggested that closure of membranous VSDs may begin in utero and the mechanism of closure was similar to that of postnatally.

The postnatal closure of the muscular septum has been hypothesized that ventricular septal closure may not be limited to the fourth and fifth postconceptive weeks, and may extend throughout pregnancy and into the postpartum period. In many cases, these muscular VSD may result from a delayed normal process rather than from disease [11]. Therefore, to avoid unnecessary anxiety, parents should be informed of this benign muscular ventricular septal defect whether it is identified by echocardiography intentionally or accidentally.
The incidence of subaterial VSD in the present study was comparable to the incidence in the West $[6,20,29]$, but much lower than that reported in Japan [18]. Although this type of VSD seldom closed spontaneously, SC patients in our study had no prolapse of the aortic valve at the time of SC. We therefore postulate that SC probably occurred by growth of muscular septum surrounding VSD. Previous studies have reported higher SC rates in smaller compared to larger defects $[13,16,26]$. In our research, Group 3 whose defects closed during gestation has the lowest average defect diameter, indicating that smaller defects are associated with better the prognosis, with a defect diameter cut-off value determined at $2.55 \mathrm{~mm}$, when the SC occurs.

Subjects with SC during gestation had the highest average birth weight, with relatively better outcomes, probably due to better blood circulation and nutrient status. Birth weight is affected by maternal and fetal genotype as well as environmental factors, and placental function is also an important factor. Levin [40] and Levy [41] reported that low birth weight infant and intrauterine growth retardation(IUGR) were more common in children with cardiovascular malformations. Levy [41] also pointed out that a hemodynamic change may explain lower birth weight by alterations of the fetal circulation. Low birth weight and prematurity and are known risks for mortality during surgery for CHD [42]. Lesions causing left to right shunt, pulmonary outflow tract obstruction or left ventricular outflow tract obstruction can severely affect intrauterine growth, resulting in small for gestational age fetuses [43]. Wei et al. [44] reported that a weight over $2.4 \mathrm{~kg}$ at the time of cardiovascular surgery was associated with lower rates of postoperative infections. Fisher et al. [45] concluded that infants with serious congenital heart disease (CHD) appear to be at increased risk for necrotizing enterocolitis (NEC). The incidence of NEC is significantly higher in very low birth weight neonates when CHD is present. We hypothesized that children with higher birth weight have a better hemodynamic and nutritional status as well as a stronger

Table 5 Fetal karyotype of the VSD

\begin{tabular}{llllll}
\hline Karyotype & Gestational weeks $(\mathrm{w})$ & Maternal ages(y) & Location & Defect diameter & Outcome \\
\hline $47, \mathrm{XY},+18$ & 26 & 26 & Membranous & $4.8 \mathrm{~mm}$ & TOP \\
$46, \mathrm{XX}, \mathrm{t}(10 ; 13)(\mathrm{p} 13 ; \mathrm{q} 14)$ & 25 & 24 & Membranous & $1.6 \mathrm{~mm}$ & Closed \\
$47, \mathrm{XX},+18$ & 24 & 32 & Mixed type & $7 \mathrm{~mm}$ & TOP \\
$45, \mathrm{X}$ & 26 & 28 & Muscular & $3 \mathrm{~mm}$ & TOP \\
$47, \mathrm{XX},+18$ & 24 & 32 & Membranous & $5.3 \mathrm{~mm}$ & TOP \\
$47, \mathrm{XX},+18$ & 23 & 43 & Membranous & $3.5 \mathrm{~mm}$ & TOP \\
$47, \mathrm{XX},+18$ & 22 & 30 & Membranous & $3.9 \mathrm{~mm}$ & TOP \\
$47, \mathrm{XX},+18$ & 22 & 25 & Membranous & $4.4 \mathrm{~mm}$ & TOP \\
$47, \mathrm{XY},+18$ & 26 & 29 & Membranous & $6.1 \mathrm{~mm}$ & TOP \\
\hline
\end{tabular}

TOP termination of pregnancy, $w$ weeks, $y$ years old 
Table 6 Single studies on spontaneous closure of ventricular septal defect

\begin{tabular}{|c|c|c|c|c|c|c|c|c|}
\hline First Author & Place(Years) & Number & Starting point & Follow up & Classification & Classification of VSD & $\begin{array}{l}\text { Spontaneous closure } \\
\text { No.(\%) }\end{array}$ & Influencing Factor \\
\hline$\overline{\text { Moe [6] }}$ & $\begin{array}{l}\text { Washington, USA } \\
\text { (1987) }\end{array}$ & 222 & after birth & $12 \mathrm{~m}$ & VSD & $\begin{array}{l}\text { perimembranous } 66(65 \%) \text {, muscular } 32(32 \%), \\
\text { subpulmonic } 3(3 \%) \text {. }\end{array}$ & $101(48 \%)$ & location \\
\hline $\begin{array}{l}\text { Hornberger } \\
{[7]}\end{array}$ & $\begin{array}{l}\text { California,USA } \\
\text { (1989) }\end{array}$ & 66 & $6 \mathrm{~m}$ & $40 \mathrm{~m}$ & VSD with CHF & perimembranous 45 , muscular 19 , supracristal 2 & $12(18 \%)$ & size \\
\hline \multirow[t]{2}{*}{$\begin{array}{l}\text { Trowitzsch } \\
{[8]}\end{array}$} & $\begin{array}{l}\text { Datteln, Germany } \\
\text { (1990) }\end{array}$ & 169 & $<4 \mathrm{w}$ & $29 \mathrm{~m}$ & & $\begin{array}{l}\text { perimembraneous } 35(20.1 \%) \text {, muscular125 }(71.8 \%) \text {, } \\
\text { malalignment } 12(6.9 \%) \text {, subpulmonary } 2(1.1 \%)\end{array}$ & $70(42.6 \%)$ & location \\
\hline & & & $4 \mathrm{w} \sim 1 \mathrm{y}$ & & & $\begin{array}{l}\text { perimembraneous } 32(33.6 \%) \text {, muscular } 57(60 \%) \text {, } \\
\text { malalignment } 6(6.3 \%)\end{array}$ & & \\
\hline Frontera [9] & $\begin{array}{l}\text { Valencia,Spain } \\
\text { (1992) }\end{array}$ & 882 & $>1 y$ & $9.5 y$ & & according toQp/Qs & $275(40.2 \%)$ & Qp/Qs \\
\hline $\begin{array}{l}\text { Ramaciotti } \\
{[10],}\end{array}$ & $\begin{array}{l}\text { Pennsylvania,USA } \\
\text { (1995) }\end{array}$ & 125 & $2.4 \mathrm{~m}$ & $32 \mathrm{~m}$ & Muscular VSD & $\begin{array}{l}\text { midmuscular } 55(44 \%) \text {, apical } 31(25 \%) \text {, anterior } 33 \\
(26 \%) \text {, and posterior } 6(5 \%)\end{array}$ & $30(31 \%)$ & \\
\hline Roguin [11], & $\begin{array}{l}\text { Nahariya, Israel } \\
\text { (1995) }\end{array}$ & 56 & $6-170 \mathrm{~h}$ & $10 \mathrm{~m}$ & Muscular VSD & & $40(88.9 \%)$ & a delayed normal process \\
\hline Du [12], & $\begin{array}{l}\text { Nahariya, Israel } \\
\text { (1996) }\end{array}$ & $9 / 159$ & $2-120 \mathrm{~h}$ & $10 \mathrm{~m}$ & $\begin{array}{l}\text { Muscular VSD } \\
\text { preterm neonate }\end{array}$ & & $8(87.5 \%)$ & \\
\hline Shirali [13], & Texas,USA (1995) & 149 & $<6 \mathrm{~m}$ & $28 \mathrm{~m}$ & & $\begin{array}{l}\text { periembranous } 100(68.9 \%) \text { muscular } 49(33.7 \%) \\
\text { canal-type } 5(3.4 \%) \text { conal-septal } 2(1.8 \%)\end{array}$ & $46(31 \%)$ & size and location \\
\hline Krovetz [14] & Florida,USA (1997) & 692 & 7 h-23y & $3 \sim 18 \mathrm{y}$ & & & $490(70.8 \%)$ & \\
\hline Turner [15] & $\begin{array}{l}\text { Newcastle,UK } \\
\text { (1999) }\end{array}$ & 68 & $2 d-42 m$ & $76 \mathrm{~m}$ & & small 49, moderate 14, large 5 . & $35.0 \%$ & location \\
\hline Paladini [16] & Naples,Italy (2000) & 68 & $24.8 \mathrm{w}$ & $1 y$ & Isolated VSD & $\begin{array}{l}\text { Perimembranous inlet } 22(32.4 \%) \text {,outlet } 19(27.9 \%) \text {; } \\
\text { muscular } 7(10.3 \%) \text {, malalignment } 16(23.5 \%)\end{array}$ & $\begin{array}{l}\text { In utero: } 46.1 \% \\
\text { postnatal : } 23.1 \% \text { not } \\
\text { close: } 30 \%\end{array}$ & size and location \\
\hline Gabriel [17], & $\begin{array}{l}\text { Vienna, Austria } \\
\text { (2002) }\end{array}$ & 222 & $20.8 y$ & $7.4 y$ & & $\begin{array}{l}\text { perimembranous } 194(84.8 \%) \text {, trabecular } 30(13.1 \%) \text {, } \\
\text { outlet infracristal } 4(1.7 \%) \text {, inlet } 1(0.4 \%) \text {. }\end{array}$ & $14(6 \%)$ & Qp/Qs \\
\hline Miyake [18] & $\begin{array}{l}\text { Osakasayama, } \\
\text { Japan (2004) }\end{array}$ & 225 & $30 \mathrm{~d} \sim 3 \mathrm{~m}$ & $6 y$ & & $\begin{array}{l}\text { perimembranous } 159(70 \%) \text { muscular } 35(16 \%) \\
\text { subpulmonary } 31(14 \%),\end{array}$ & $107(48 \%)$ & location \\
\hline Atalay [19] & $\begin{array}{l}\text { Ankara, Turkey } \\
\text { (2005) }\end{array}$ & 42 & $<6 \mathrm{~m}$ & $2 \sim 10 y$ & $\begin{array}{l}\text { Small Apical } \\
\text { Muscular VSD }\end{array}$ & & $24(57.1 \%)$ & neonatal period \\
\hline $\begin{array}{l}\text { Fliedner } \\
\text { [20] }\end{array}$ & $\begin{array}{l}\text { Bonn, Germany } \\
(2006)\end{array}$ & 146 & $23.4 \mathrm{w}$ & 1y & Isolated VSD & $\begin{array}{l}\text { perimembranous } 15(10.3 \%) \text { muscular } 131(89.7 \%) \text { : } \\
\text { trabecular } 116(79.5 \%) \text {, outlet } 12(8.2 \%) \text {, inlet } 3(2 \%) \text {. }\end{array}$ & $\begin{array}{l}\text { in utero: } 32.7 \% \\
\text { postnatal: } 44.3 \% \text { not } \\
\text { close: } 23.0 \%\end{array}$ & location \\
\hline Abbag [39] & $\begin{array}{l}\text { Saudi Arabia } \\
\text { (2006) }\end{array}$ & 86 & $14 \mathrm{~m}$ & $66.3 \mathrm{~m}$ & & $\begin{array}{l}\text { perimembranous } 67.4 \% \text {, muscular } 19.8 \% \text {, inlet } 7 \% \\
\text { subarterial } 5.8 \% \text {. }\end{array}$ & $16.30 \%$ & age, size \\
\hline Atik [21] & $\begin{array}{l}\text { São Paulo Brazil } \\
\text { (2008) }\end{array}$ & 155 & $8 d$ & $1-18 Y$ & Small VSD & perimembranous 68 (36.3\%) muscular 119 (63.6\%) & $48(75 \%)$ & location \\
\hline Miyake [22], & $\begin{array}{l}\text { Osaka, Japan } \\
\text { (2008) }\end{array}$ & 48 & $2 y$ & $17.8 \mathrm{y}$ & $\begin{array}{l}\text { Perimembranous } \\
\text { VSD }\end{array}$ & according to Qp/Qs & $11(23 \%)$ & Qp/Qs \\
\hline
\end{tabular}


Table 6 Single studies on spontaneous closure of ventricular septal defect (Continued)

\begin{tabular}{|c|c|c|c|c|c|c|c|c|}
\hline Chang [23] & $\begin{array}{l}\text { Kaohsiung, } \\
\text { Taiwan (2010) }\end{array}$ & 66 & & $1 y$ & MuscularVSD & midmuscular 37, apical 24, anterior 5 & $54(81.8 \%)$ & \\
\hline $\operatorname{Jin}[24]$ & $\begin{array}{l}\text { Shandong, China } \\
\text { (2012) }\end{array}$ & 96 & $24 \sim 40 w$ & $3 y$ & & $\begin{array}{l}\text { Perimembranous 14, } \\
\text { Muscular } 52\end{array}$ & $\begin{array}{l}\text { in utero: } 3 \% \text {, postnatal: } \\
83.3 \% \text { not close: } 3.9 \%\end{array}$ & size and location \\
\hline Sun [25] & $\begin{array}{l}\text { Shanghai, China } \\
\text { (2014) }\end{array}$ & 1873 & $1 \sim 6 y$ & $23.8 \mathrm{~m}$ & $\begin{array}{l}\text { Perimembranous } \\
\text { VSD }\end{array}$ & & $343(18.3 \%)$ & $\begin{array}{l}\text { Age diamete, Diffuse } \\
\text { shunt flow, aneurysmal tissue }\end{array}$ \\
\hline Erol [26] & $\begin{array}{l}\text { Istanbul, Turkey } \\
\text { (2014) }\end{array}$ & 76 & $23.1 \mathrm{w}$ & $1 y$ & Muscular VSD & & $\begin{array}{l}\text { in utero: } 6.8 \% \text {, } \\
\text { postnatal: } 75 \% \text {, not } \\
\text { close: } 18.2 \%\end{array}$ & size \\
\hline Xu [27] & $\begin{array}{l}\text { Changchun, } \\
\text { China (2015) }\end{array}$ & 425 & $1 \mathrm{~d} \sim 6 \mathrm{~m}$ & $5 y$ & & $\begin{array}{l}\text { Perimembranous313 (73.65\%) muscular } 53(12.47 \%) \\
\text { subarterial } 39 \text { (9.18\%) mixed-type } 20(4.70 \%) .\end{array}$ & $93(21.8 \%)$ & $\begin{array}{l}\text { size, location, } \mathrm{Qp} / \mathrm{Qs} \text {, } \\
\text { membranous septal aneurysm }\end{array}$ \\
\hline
\end{tabular}

Congestive heart failure $\mathrm{CHF}$ 
immunity to fight against infection. In this case, the growth and development of children with higher birth weight were less susceptible to be affected by infections. Further studies on fetal anthropometry and haemodynamics are necessary to provide insight into the relationship between cardiovascular malformations and low birth weight. In addition, reports of SC rates in utero are highly variable (3-46.1\%), with average defects measuring $1.5-2 \mathrm{~mm}$ in size $[16,20,26,28]$. In the present research, this compared with $19.1 \%$ SC rate in utero.

VSDs can increase the risk of aneuploidy of the affected fetus and fetal karyotyping should be offered. Since not all cases in our study received serum screening, control for this possibility with regards to iVSD closure has been reported by Lee et al. [46], who found that presence of an i-VSD before 24 weeks does increase the risk of fetal aneuploidy. Extensive examination for extracardiac anomalies should also be performed. Furthermore, studies have demonstrated gender-based differences in fetal cardiac diseases [47], and the SC rate of male patients was higher than female patients in the current investigation. However, the causes of genderbased differences in cardiac disease are still not completely clear and require further investigation.

There were a number of limitations in the present study. Only $76.7 \%$ of patients agreed to echocardiographic reexamination, which may have affected the SC rates. In addition, the subjects included in the evaluation were young children, and SC rates may increase with advancing age. Due to these limitations, the available evidence allows for crude estimates and only in children aged 2 years and under. Therefore, assessment of long-term prognosis, especially in children beyond this age, is imperative.

\section{Conclusion}

In summary, birth weight and prenatal echocardiographic measurement of size and location of VSD enables the estimation of SC probability in individual patients. These data would be particularly informative for patients whose defect diameter indicates a high SC probability. Information from this study can be used in counseling of patients' families by helping them prepare for the possible outcome of their child's disease.

\section{Abbreviations}

CHD: Congenital heart disease; CHF: Congestive heart failure;

SC: Spontaneously closure; TOP: Termination of pregnancy; VSD: Ventricular septal defect

\section{Acknowledgements}

We thank all participating medical centers for their help in this study. We would like to thank all the parents and children who took part in the original study and those who kindly shared their experiences throughout the interviews.
Funding

Supported by the National Natural Science Foundation of China (Grant No. 81370278 and No.81300127).

\section{Availability of data and materials}

The Ethics Board did not allow to publicly share the data and materials of this study. These data and materials could be available upon request to the corresponding author and in accordance with the Ethics Board.

\section{Authors' contributions \\ $\mathrm{XL}(\mathrm{PhD})$ and GXS (PhD) drafted the initial manuscript, contributed to the collection, analysis, and interpretation of the data, and approved the final manuscript as submitted. LJW (MS), YMC (MS), YF (MS) and YHS (MS) contributed to collection of the data and revision of the manuscript. YW (MD) conducted most of the fetal echocardiography. Professor LC (PhD) was responsible for the design of the study, contributed to the interpretation of the data, critically revised the manuscript, and approved the final manuscript as submitted. Professor LMQ (PhD) conceptualized the study, was responsible for the design of the study, contributed to the collection and the interpretation of the data, critically revised the manuscript, and approved the final manuscript as submitted. XL and GXS contributed equally to this work. Prof. LMQ and Prof. LC are both corresponding authors. All authors read and approved the final manuscript.}

\section{Competing interests}

The authors declare that they have no competing interest.

Consent for publication

Not Applicable.

Ethics approval and consent to participate

Each participant provided written, informed consent prior to inclusion in this study. This study is in compliance with the Helsinki Declaration. The results reported in this article had been approved by the Ethics Committee of the First Affiliated Hospital of Nanjing Medical University, with ethical application number:2011-SR-132.

Written informed consent was obtained from the parents of the patient for publication.

\section{Author details}

'Department of Cardiology, Wuxi Second Hospital, Nanjing Medical University, No.68 Zhongshan Road, Wuxi, Jiangsu Province, China. ${ }^{2}$ Department of Cardiology, The First Affiliated Hospital of Nanjing Medical University, No. 300 Guangzhou Road, Nanjing 210029, Jiangsu Province, China. ${ }^{3}$ Department of Fetal Echocardiography, Nanjing Maternity and Child Health Care Hospital Affiliated to Nanjing Medical University, No.123 Tianfei Lane, Mochou Road, Nanjing, Jiangsu Province, China. ${ }^{4}$ Department of Cardiology, Jiangsu Taizhou People's Hospital, Taizhou, Jiangsu Province, China

Received: 3 September 2015 Accepted: 23 November 2016

Published online: 08 December 2016

\section{References}

1. Hoffman J. Incidence of congenital heart disease: I. Postnatal incidence. Pediatr Cardiol. 1995;16(3):103-13.

2. Hoffman JI, Kaplan S. The incidence of congenital heart disease. J Am Coll Cardiol. 2002:39(12):1890-900.

3. Zhao QM, Ma XJ, Jia B, Huang GY. Prevalence of congenital heart disease at live birth: an accurate assessment by echocardiographic screening. Acta Paediatr. 2013;102(4):397-402.

4. Rothman K, Fyler DC. Seasonal occurrence of complex ventricular septal defect. Lancet. 1974;2(7874):193-7.

5. Newman TB. Etiology of ventricular septal defects: an epidemiologic approach. Pediatrics. 1985;76(5):741-9.

6. Moe DG, Guntheroth WG. Spontaneous closure of uncomplicated ventricular septal defect. Am J Cardiol. 1987;60(8):674-8.

7. Hornberger LK, Sahn DJ, Krabill KA, Sherman FS, Swensson RE, Pesonen E, et al. Elucidation of the natural history of ventricular septal defects by serial Doppler color flow mapping studies. J Am Coll Cardiol. 1989;13(5):1111-8. 
8. Trowitzsch E, Braun W, Stute M, Pielemeier W. Diagnosis, therapy, and outcome of ventricular septal defects in the 1st year of life: a twodimensional colour-Doppler echocardiography study. Eur J Pediatr. 1990;149(11):758-61.

9. Frontera-Izquierdo P, Cabezuelo-Huerta G. Natural and modified history of isolated ventricular septal defect: a 17-year study. Pediatr Cardiol. 1992;13(4):193-7.

10. Ramaciotti C, Vetter JM, Bornemeier RA, Chin AJ. Prevalence, relation to spontaneous closure, and association of muscular ventricular septal defects with other cardiac defects. Am J Cardiol. 1995;75(1):61-5.

11. Roguin N, Du ZD, Barak M, Nasser N, Hershkowitz S, Milgram E. High prevalence of muscular ventricular septal defect in neonates. J Am Coll Cardiol. 1995;26(6):1545-8.

12. Du ZD, Roguin N, Barak M, Bihari SG, Ben-Elisha M. High prevalence of muscular ventricular septal defect in preterm neonates. Am J Cardiol. 1996;78(10):1183-5.

13. Shirali GS, Smith EO, Geva T. Quantitation of echocardiographic predictors of outcome in infants with isolated ventricular septal defect. Am Heart J. 1995;130(6):1228-35.

14. Krovetz LJ. Spontaneous closure of ventricular septal defect. Am J Cardiol. 1998;81(1):100-1.

15. Turner SW, Hunter S, Wyllie JP. The natural history of ventricular septal defects. Arch Dis Child. 1999;81(5):413-6.

16. Paladini D, Palmieri S, Lamberti A, Teodoro A, Martinelli P, Nappi C. Characterization and natural history of ventricular septal defects in the fetus. Ultrasound Obstet Gynecol. 2000;16(2):118-22.

17. Gabriel HM, Heger M, Innerhofer P, Zehetgruber M, Mundigler G, Wimmer M, et al. Long-term outcome of patients with ventricular septal defect considered not to require surgical closure during childhood. J Am Coll Cardiol. 2002; 39(6):1066-71.

18. Miyake T, Shinohara T, Nakamura Y, Fukuda T, Tasato H, Toyohara K, et al. Spontaneous closure of ventricular septal defects followed up from $<3$ months of age. Pediatr Int. 2004;46(2):135-40.

19. Atalay S, Tutar E, Ekici F, Nacar N. Spontaneous closure of small apical muscular ventricular septal defects. Turk J Pediatr. 2005;47(3):247-50.

20. Axt-Fliedner R, Schwarze A, Smrcek J, Germer U, Krapp M, Gembruch U. Isolated ventricular septal defects detected by color Doppler imaging: evolution during fetal and first year of postnatal life. Ultrasound Obstet Gynecol. 2006;27(3):266-73.

21. Abbag F. The natural history of ventricular septal defects in the southwestern region of Saudi Arabia. Ann Trop Paediatr. 2006:26(3):215-8.

22. Atik E. Small ventricular septal defect: long-term expectant clinical management. Arq Bras Cardiol. 2009;92(6):396. -9, 413-6, 29-32.

23. Miyake T, Shinohara T, Fukuda T, Ikeoka M, Takemura T. Spontaneous closure of perimembranous ventricular septal defect after school age. Pediatr Int. 2008;50(5):632-5.

24. Bahtiyar MO, Dulay AT, Weeks BP, Friedman AH, Copel JA. Prenatal course of isolated muscular ventricular septal defects diagnosed only by color Doppler sonography: single-institution experience. J Ultrasound Med. 2008:27(5):715-20.

25. Chang JK, Jien WY, Chen HL, Hsieh KS. Color Doppler echocardiographic study on the incidence and natural history of early-infancy muscular ventricular septal defect. Pediatr Neonatol. 2011;52(5):256-60.

26. Jin $Y$, Wang $A$, Wang $Y$, Wang $Y$, Wang $W$, Hou $X$. Natural history of prenatal ventricular septal defects and their association with foetal echocardiographic features. Cardiol Young. 2012;22(3):323-6.

27. Sun J, Sun K, Chen S, Yao L, Zhang Y. A new scoring system for spontaneous closure prediction of perimembranous ventricular septal defects in children. PLoS One. 2014;9(12):e113822.

28. Erol O, Sevket O, Keskin S, Yazicioglu HF, Gul A. Natural history of prenatal isolated muscular ventricular septal defects. J Turk Ger Gynecol Assoc. 2014;15(2):96-9.

29. Xu Y, Liu J, Wang J, Liu M, Xu H, Yang S. Factors influencing the spontaneous closure of ventricular septal defect in infants. Int J Clin Exp Pathol. 2015; 8(5):5614-23.

30. Soto B, Becker AE, Moulaert AJ, Lie JT, Anderson RH. Classification of ventricular septal defects. Br Heart J. 1980;43(3):332-43.

31. International Society of Ultrasound in O, Gynecology, et al. ISUOG Practice Guidelines (updated): sonographic screening examination of the fetal heart. Ultrasound Obstet Gynecol. 2013;41(3):348-59.
32. American Institute of Ultrasound in Medicine. AlUM practice guideline for the performance of fetal echocardiography. J Ultrasound Med. 2011;30(1): 127-36.

33. Saxena A, Soni NR. Fetal echocardiography: where are we? Indian J Pediatr. 2005;72(7):603-8.

34. Small M, Copel JA. Indications for fetal echocardiography. Pediatr Cardiol. 2004:25(3):210-22

35. French $\mathrm{H}$. The possibility of a loud congenital murmur disappearing when a child grows up. Guys Hosp Gaz. 1919;32:87.

36. Nir A, Weintraub Z, Oliven A, Kelener J, Lurie M. Anatomic evidence of spontaneous intrauterine closure of a ventricular septal defect. Pediatr Cardiol. 1990;11(4):208-10.

37. Suzuki H. Spontaneous closure of ventricular septal defects. Anatomic evidence in six adult patients. Am J Clin Pathol. 1969;52(4):391-402.

38. Anderson RH, Lenox CC, Zuberbuhler JR. Mechanisms of closure of perimembranous ventricular septal defect. Am J Cardiol. 1983;52(3):341-5.

39. Nir A, Driscoll DJ, Edwards WD. Intrauterine closure of membranous ventricular septal defects: mechanism of closure in two autopsy specimens. Pediatr Cardiol. 1994;15(1):33-7.

40. Levin DL, Stanger P, Kitterman JA, Heymann MA. Congenital heart disease in low birth weight infants. Circulation. 1975;52(3):500-3.

41. Levy RJ, Rosenthal A, Fyler DC, Nadas AS. Birthweight of infants with congenital heart disease. Am J Dis Child. 1978;132(3):249-54.

42. Dimmick S, Walker K, Badawi N, Halliday R, Cooper SG, Nicholson IA, et al. Outcomes following surgery for congenital heart disease in low-birthweight infants. J Paediatr Child Health. 2007:43(5):370-5.

43. Jacobs EG, Leung MP, Karlberg J. Birthweight distribution in southern Chinese infants with symptomatic congenital heart disease. J Paediatr Child Health. 2003;39(3):191-6.

44. Wei D, Azen C, Bhombal S, Hastings L, Paquette L. Congenital heart disease in low-birth-weight infants: effects of small for gestational age (SGA) status and maturity on postoperative outcomes. Pediatr Cardiol. 2015;36(1):1-7.

45. Fisher JG, Bairdain S, Sparks EA, Khan FA, Archer JM, Kenny M, et al. Serious congenital heart disease and necrotizing enterocolitis in very low birth weight neonates. J Am Coll Surg. 2015;220(6):1018-26. e14.

46. Lee G, Fong SX, Salpekar M, Satterwhite CL, Weiner C. Is an isolated ventricular septal defect detected before 24 weeks on ultrasound associated with fetal aneuploidy? J Matern Fetal Neonatal Med. 2016;29(10):1687-90.

47. Yang PC, Clancy CE. Gender-based differences in cardiac diseases. J Biomed Res. 2011:25(2):81-9.

\section{Submit your next manuscript to BioMed Central and we will help you at every step:}

- We accept pre-submission inquiries

- Our selector tool helps you to find the most relevant journal

- We provide round the clock customer support

- Convenient online submission

- Thorough peer review

- Inclusion in PubMed and all major indexing services

- Maximum visibility for your research

Submit your manuscript at www.biomedcentral.com/submit
C) Biomed Central 